\title{
Particle Concentration Comparison of Radiator and Floor Heating Systems under Zero Air Change Rate Condition
}

\author{
Mustafa Mutlu*
}

Air Conditioning and Refrigeration Technology Program, Vocational School of Yenisehir Ibrahim Orhan, Bursa Uludag University, 16900 Yenisehir, Bursa, Turkey

\begin{abstract}
As a result of isolating doors and windows very well to reduce heating energy costs, some environments' air change rate becomes zero. Two different heating systems (radiator and floor heating systems) widely used in residential applications were compared for a room where the air change rate is zero, using numerical methods in terms of particle concentrations. 3D dimensional CFD simulations show that the floor heating system performs better in removing the pollutants dispersed homogeneously in the room, while the radiator system is more effective in removing the pollutants emitted from a source close to the floor. It was concluded that special care should be taken not to have a source of pollutants close to the ground surface in the environments where a floor heating system is used.
\end{abstract}

Keywords: Indoor air, Particle distribution, Radiator heating, Floor heating, Zero air change

\section{INTRODUCTION}

There has been a long-standing interest in indoor air quality in living areas (offices, houses, fitness halls, etc.) regarding public health when it is considered that people spend most of their time in enclosed areas because of modifications to their lifestyle. Particularly, airborne particulate matter (PM) poses a severe health risk. Limit concentration values of particles that smaller than $10 \mu \mathrm{m}$ and $2.5 \mu \mathrm{m}$ diameter for short term exposure is $50 \mu \mathrm{g} \mathrm{m}^{-3}$ and $25 \mu \mathrm{g} \mathrm{m}^{-3}$, respectively, according to World Health Organization (2006). Understanding pollutant concentration distribution in the living environment is one of the primary objective of indoor air quality evaluation and exposure levels. Air velocity characteristics in a room significantly affect airborne particle concentration as particles whose diameter is between 5-10 $\mu \mathrm{m}$ move under air movements' influence (Owen et al., 1992). Therefore, the air velocity in the heated environment is a crucial parameter regarding particle concentration and every heating system causes a specific air movement in the room. These two heating systems has their own specific velocity and temperature profiles in the room as well as particle motion characteristics. In heating periods, different heating systems can be used to heat residential buildings. The most common of these systems is floor heating and radiator heating systems. In the radiator heating system, water, transported by pipes from the heating device, heats the room by flowing through a radiator. In the floor heating system, the place is heated up by hot water that flows through pipes laid under the floor. It was reported that as the floor heating system could be operated at low temperatures, it consumes less energy than the radiator heating system (Kazanci et al., 2016).

Golkarfard and Talebizadeh (2014) were one of the first who compared the floor and radiator heating systems in terms of particle distributions in a room. They examined the effect of two different heating systems (radiator and floor heating systems) on the distribution of particles released from a source in the middle of the room. In their research, in which CFD is used, heating systems' effect on particle distribution was examined as the primary variable as well as the 
particle diameter. They found that the particle deposition rate reached $100 \%$ after 80 seconds when using floor heating systems, but it was slightly above $90 \%$ after 200 seconds in the radiator heating system. They also examined the particle adhesion rate on room surfaces, calculated that the particles adhere more to the ceiling surface than the radiator system when using the floor heating system. However, they observed that particles adhere more to the floor than the ceiling in using the radiator heating system. They found that the particle adhesion rate on the side walls was not affected by the heating system. Zhou et al. (2017) examined the effect of ventilation in the floor heating system using CFD analysis verified with experimental data. Ventilation type (inlet from below or above), inlet air velocity and floor temperature were studied in their research. They found that in the case of up-supply ventilation, the particles are concentrated in the middle of the room and their concentration values decrease as the floor temperature increases. However, if the air inlet velocities remain constant, increasing the floor temperature advances the particle removal rate from the environment, and when the floor temperature is stable, increasing the air inlet velocity causes the same effect. They reported that when the temperature difference between the floor and walls is low $(5 \mathrm{~K}, 10 \mathrm{~K})$, the ventilation type does not affect the particle removal rate, while the significant temperature differences $(15 \mathrm{~K})$ has a slight effect.

Dehghan and Abdolzadeh (2018) investigated the particle distribution and concentration characteristics in a room formed in a mannequin's breathing zone in the middle of the room with CFD simulations involving three different heating systems, including radiators and underfloor heating systems. They examined the particle concentration values in various planes, particle adhesion rate on room surfaces, and the effect of particle diameter. They also found that the highest particle concentration in the mannequin's breathing zone was in the radiator heating system. They reported that particle deposition behavior to the floor surface and other walls is affected by the heating systems. In contrast, particles' deposition rate to the ceiling surface is similar in radiator and floor heating systems. They observed that while the particles deposit to the floor more in a radiator heating system, they deposit more to the walls other than the floor when the floor heating system is used. They concluded that particle deposition fraction does significantly alters with particle diameter. Radiator and floor heating systems were experimentally compared regarding particle concentrations in a room by Ghasemi et al. (2020). They investigated the particle distribution in a room by measuring the particle concentrations collected with a vacuum cleaner and placed on the floor after sieving. Since they worked under continuous regime conditions, particle concentrations were reported in eight different room locations instead of the particle concentrations variation by time like other researchers did. In the radiator heating system, particle concentrations in the room were measured higher than the floor heating system and it was concluded that the use of carpet does not affect the particle concentrations. When considering previous research about radiator and floor heating systems in terms of indoor air quality, it can be said that generally, the deviation of particle concentrations by time in an environment is examined and the deposition rate of particles is investigated. With the CFD method, the particle concentrations in the breathing zone can be easily analyzed. Regardless of which heating system is preferred, people choose to insulate the rooms they heat very well for energy-saving purposes. This insulation, made with energy costs concerns, causes a severe drop in the room's air change rate, which may be equal to zero or close to zero. The insulation significantly impacts particle concentrations, considering that particle movement is notably affected by air velocities. Taken together, it remains an open question how zero air change rate affect the particle distributions in a room when floor or radiator heating system was used.

The goal of the present article is to compare particle concentration levels of floor heating and radiator heating systems in a room with zero air change rate. I predict that zero air change has a significant role on particle distribution as well as heating system type. To answer this question, I used CFD simulations to determine the particle concentrations variation by time in the room and the deposition rates on room surfaces like other studies. Besides, by identifying the pollutant source at five different room locations, the steady-state particle concentrations were investigated.

\section{MATERIAL AND METHOD}

In this study, a commercial code Ansys Fluent was used to track particles and obtain velocity 
and temperature distribution in a room. Firstly, velocity and temperature distribution were solved in steady-state conditions for both heating systems. Then particles were tracked under transient regime conditions using the discrete phase model (DPM). In this model, the flow phase is calculated by solving the Navier-Stokes equations. At the same time, particle tracking is determined by the force balance that acting on particles. Momentum, energy, and mass can transfer between the particles and the flow phase. Similar approaches were used by many researchers (Abdolzadeh et al., 2019; Memarzadeh and Manning, 2002; Tao et al., 2020; Zhao et al., 2008; Zhou et al., 2017). The room structure of the experimental design of Olesen et al. (1980), where different heating systems had been examined, was used in the CFD simulations. Although it is an old study, the experimental data obtained maintains its reliability and is taken as a reference in current studies (Anthony and Verma, 2021; Ye et al., 2021, 2020). Moreover, the study results are still used for validation in CFD studies (Dehghan and Abdolzadeh, 2018). After obtaining the temperature and velocity distributions numerically, the motion of particles, which was initially random-distributed in the room, was calculated. Then, five different pollutant source locations in the room were studied to identify how pollutant location affects the particle concentration values.

\subsection{Room Geometry and Heating Systems}

In CFD simulations, the calculation volume was designed based on the office-sized room used in Olesen et al. (1980) experiments. The dimensions and size of the room were given in Fig. 1.

The floor heating system was modeled by defining heat flux boundary condition to the floor surface, while the radiator heating system is modeled with a $2.0 \mathrm{~m}$ long $0.55 \mathrm{~m}$ high radiator placed under the window. The power of both heating systems was determined by calculating the heat losses when the room was $22^{\circ} \mathrm{C}$. Heat losses were calculated using the total heat transfer coefficients given by Olesen et al. (1980).

\subsection{Numerical Model}

Air movements in a fully insulated room with a zero air exchange rate are under the influence of gravitational forces. The density changes of the air in the control volume where there is no
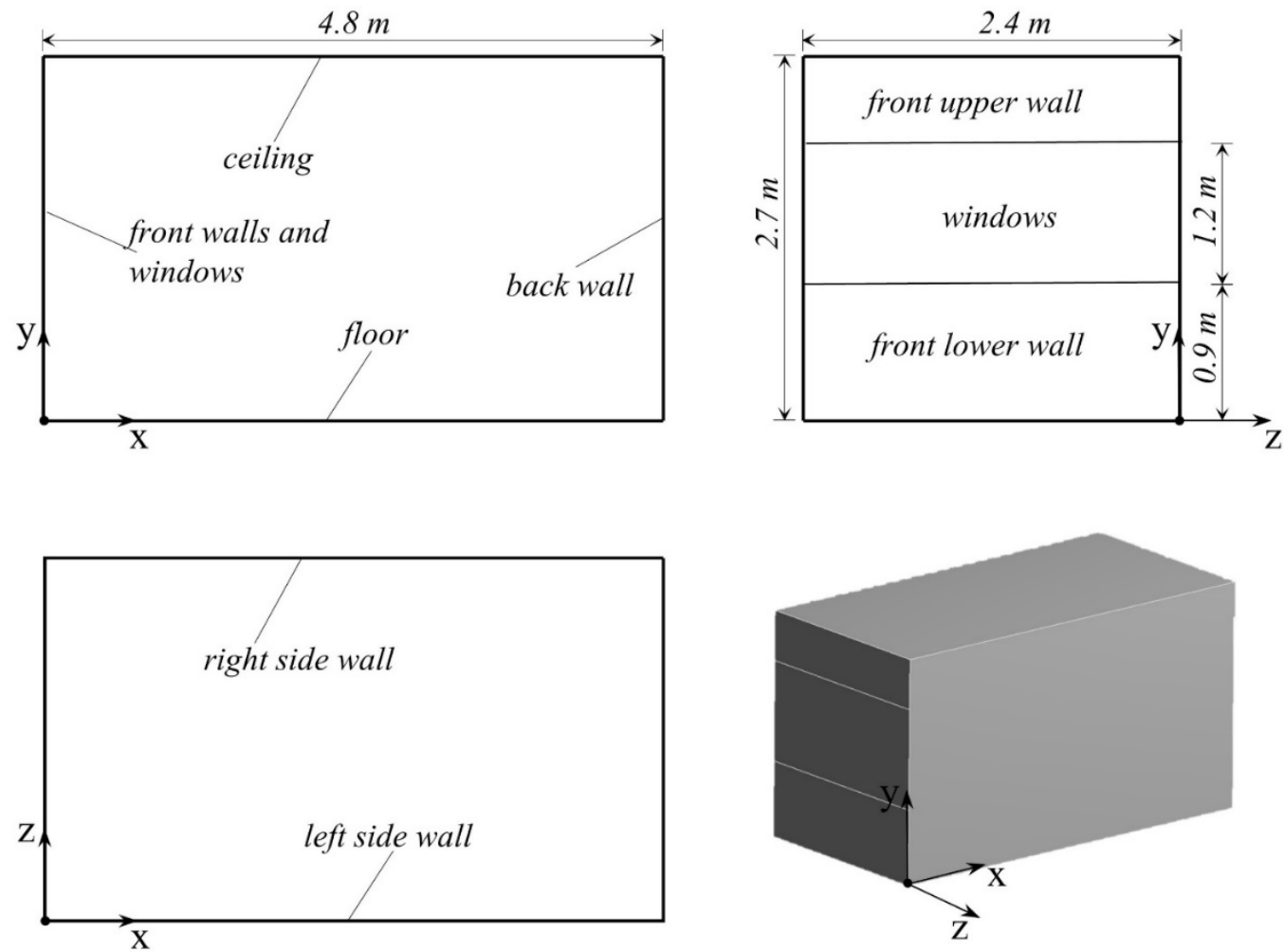

Fig. 1. Room geometry and dimensions used in CFD calculations. 
Table 1. Details of boundary conditions.

\begin{tabular}{|c|c|c|c|c|}
\hline \multirow{2}{*}{ Boundary } & \multicolumn{2}{|c|}{ Condition in Floor Heating System } & \multicolumn{2}{|c|}{ Condition in Radiator Heating System } \\
\hline & Momentum & Thermal & Momentum & Thermal \\
\hline Floor & No-Slip, & Heat Flux: $41.25 \mathrm{~W} \mathrm{~m}^{-3}$ & No-Slip, & \\
\hline Ceiling & Stationary & Mixed; Heat Transfer Coefficient: & Stationary & Mixed; Heat Transfer Coefficient: \\
\hline Back Wall & Wall & $7 \mathrm{~W} \mathrm{~m}^{-2} \mathrm{~K}^{-1}$ & Wall & $7 \mathrm{~W} \mathrm{~m}^{-2} \mathrm{~K}^{-1}$ \\
\hline Side Walls & & Free Stream Temperature: $-5^{\circ} \mathrm{C}$ & & Free Stream Temperature: $-5^{\circ} \mathrm{C}$ \\
\hline Window & & External Radiation Temperature: $-5^{\circ} \mathrm{C}$ & & External Radiation Temperature: $-5^{\circ} \mathrm{C}$ \\
\hline \multirow[t]{6}{*}{ Front Walls } & & Internal Emissivity: 0.9 & & Internal Emissivity: 0.9 \\
\hline & & Opaque BC for Radiation & & Opaque BC for Radiation \\
\hline & & $\mathrm{U}_{\text {ceiling }}=0.25 \mathrm{~W} \mathrm{~m}^{-2} \mathrm{~K}^{-1}$ & & $\mathrm{U}_{\text {ceiling }}=0.25 \mathrm{~W} \mathrm{~m}^{-2} \mathrm{~K}^{-1}$ \\
\hline & & $\mathrm{U}_{\text {walls }}=0.25 \mathrm{~W} \mathrm{~m}^{-2} \mathrm{~K}^{-1}$ & & $\mathrm{U}_{\text {walls }}=0.25 \mathrm{~W} \mathrm{~m}^{-2} \mathrm{~K}^{-1}$ \\
\hline & & $\mathrm{U}_{\text {window }}=3.8 \mathrm{~W} \mathrm{~m}^{-2} \mathrm{~K}^{-1}$ & & $\mathrm{U}_{\text {window }}=3.8 \mathrm{~W} \mathrm{~m}^{-2} \mathrm{~K}^{-1}$ \\
\hline & & & & $\mathrm{U}_{\text {floor }}=0.2 \mathrm{~W} \mathrm{~m}^{-2} \mathrm{~K}^{-1}$ \\
\hline Radiator Walls & & & & Heat Flux: $180 \mathrm{~W} \mathrm{~m}^{-3}$ \\
\hline
\end{tabular}

inlet has been calculated using the incompressible ideal gas approach in this problem. Momentum, velocity and energy equations (Eqs. (1)-(3)) have been solved using ANSYS Fluent software, and the low Reynolds k- $\varepsilon$ turbulence model has been used.

$$
\begin{aligned}
& \frac{\partial \rho}{\partial t}+\nabla \cdot(\rho \vec{v})=0 \\
& \frac{\partial}{\partial t}(\rho \vec{v})+\nabla \cdot(\rho \vec{v} \vec{v})=-\nabla p+\nabla \cdot(\bar{\tau})+\rho \vec{g}+\vec{F} \\
& \frac{\partial}{\partial t}(\rho E)+\nabla \cdot(\vec{v}(\rho E+p))=-\nabla\left(\sum_{j} h_{j} J_{j}\right)+S_{h}
\end{aligned}
$$

This turbulence model was chosen by many researchers in similar studies (Myhren and Holmberg, 2008; Sakai et al., 2011). In simulations, PRESTO! method, SIMPLEC algorithm and second-order discretization were applied. The boundary conditions were given in Table 1.

Considering the real conditions, heat transfer between the room surfaces and the outdoor environment occurs by convection and radiation mechanisms. Instead of modeling the effect of both mechanisms with a single heat transfer coefficient, convection and radiation heat losses from surfaces were calculated using boundary conditions. The heat transfer coefficient was taken as $7 \mathrm{~W} \mathrm{~m}^{-2} \mathrm{~K}^{-1}$ in this study, where given equations could calculate this value in previous studies (Liu et al., 2015).

\subsection{Particle Tracking}

After obtaining the velocity and temperature distributions in steady-state conditions, 30000 particles were randomly distributed into the room to calculate particle concentration variation by time. For calculating the concentration values correctly, the results must be independent of the particle number. Therefore, analyzes were carried out with 5000, 10000, 20000, 30000 and 50000 particles to determine particle number in which the results did not change. According to the results, the particle concentration values in the room did not change after 30000 particles. The particle density was taken as $870 \mathrm{~kg} \mathrm{~m}^{-3}$, which is the same density of house dust measured in the experimental study by Ghasemi et al. (2020). The particle tracking has been done with the discrete phase model (DPM) and the balance of force on a particle is as follows:

$$
\frac{\partial \vec{u}_{p}}{\partial t}=F_{D}\left(\vec{u}-\vec{u}_{p}\right)+\frac{\vec{g}\left(\rho_{p}-\rho\right)}{\rho_{p}}+\vec{F}
$$


It was assumed that drag (Eq. (5)), thermophoresis (Eq. (6)), Brownian (Eq. (7)) and Saffman lift (Eq. (8)) forces affect particle motions.

$F_{D}=\frac{18 \mu}{\rho_{p} d_{p}^{2}} \frac{C_{D} R e}{24}$

$\vec{F}=-\frac{6 \pi d_{p} u^{2} C_{s}\left(K+C_{t} K n\right)}{\rho\left(1+3 C_{m} K n\right)\left(1+2 K+2 C_{t} K n\right)} \frac{1}{m_{p} T} \nabla \mathrm{T}$

$F_{b}=\zeta \sqrt{\frac{216 v k_{B} T}{\pi \rho d_{p}^{2}\left(\frac{\rho_{p}}{\rho}\right)^{2} C_{c} \Delta t}}$

$\vec{F}=\frac{2 K v^{1 / 2} \rho d_{i j}}{\rho_{p} d_{p}\left(d_{l k} d_{k l}\right)^{1 / 4}}\left(\vec{u}-\vec{u}_{p}\right)$

Five point-type particle sources at different locations of $0.1 \mathrm{~m}$ above the floor were defined to examine the particle source's effect. While two sources were close to the window, another two sources were located near the back wall. The other source was placed in the middle of the room (Fig. 2).

The particle diameter, density and mass flow rate were taken as $1 \mu \mathrm{m}, 1600 \mathrm{~kg} \mathrm{~m}^{-3}$ and $2.4 \mathrm{mg} \mathrm{h}^{-1}$ (6.67e-10 $\mathrm{kg} \mathrm{h}^{-1}$ ) to simulate the particle sources as a burning candle (Pagels et al., 2009). The trap boundary condition was applied to room surfaces and the same assumption was made by many researchers (Chen, 2018; Han et al., 2011; Sadrizadeh and Holmberg, 2015; Tao et al., 2020; Wang and Wang, 2020; Zhou et al., 2017). A line in the middle of the room ( $z=-1.2 \mathrm{~m})$ and $1.5 \mathrm{~m}$ above the floor was determined to compare the particle concentrations between heating systems using a concentration ratios (CR) parameter defined by Eq. (9).

$C R=\frac{C_{F H}}{C_{R H}}$

Here, $C_{F H}$ and $C_{R H}$ represent the particle concentration in the floor heating and the radiator heating systems.

\subsection{Validation}

For the accuracy of the results, velocity and temperature distributions were compared with the

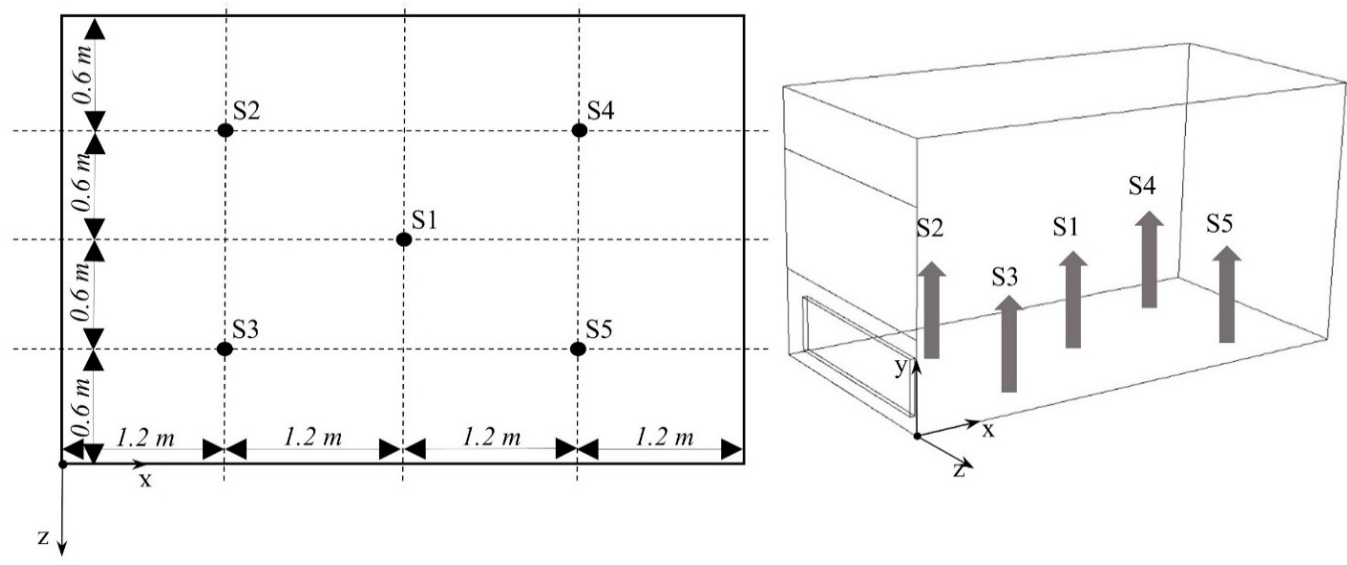

Fig. 2. Presentation of particle source locations in the room. 

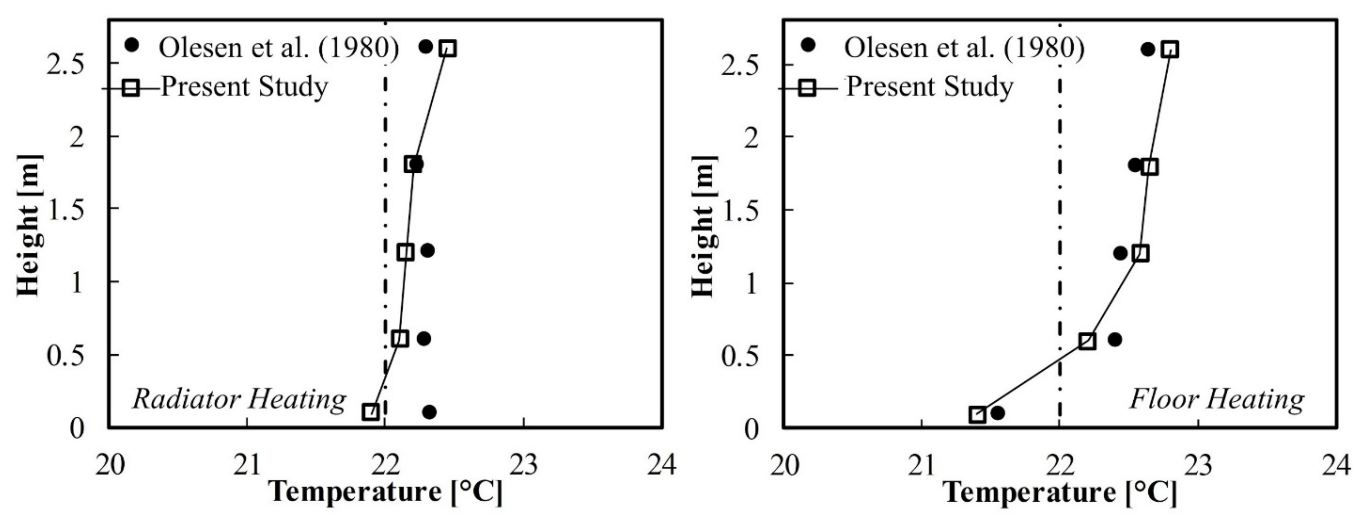

Fig. 3. Comparison of numerical results of temperature values with the experimental study of Olesen et al. (1980).

Table 2. Comparison of velocity values.

\begin{tabular}{|c|c|c|c|c|c|c|}
\hline \multicolumn{3}{|c|}{ Position } & \multicolumn{2}{|c|}{ Radiator Heating } & \multicolumn{2}{|c|}{ Floor Heating } \\
\hline$x$ & $\mathrm{Y}$ & Z & Measured (Std. Dev.) & Calculated & Measured (Std. Dev.) & Calculated \\
\hline 0.6 & 1.2 & -1.2 & $9(5) \mathrm{cm} \mathrm{s}^{-1}$ & $4.56 \mathrm{~cm} \mathrm{~s}^{-1}$ & - & $0.7 \mathrm{~cm} \mathrm{~s}^{-1}$ \\
\hline 1.8 & 0.1 & -1.2 & - & $7.3 \mathrm{~cm} \mathrm{~s}^{-1}$ & $13(2) \mathrm{cm} \mathrm{s}^{-1}$ & $12.21 \mathrm{~cm} \mathrm{~s}^{-1}$ \\
\hline 0.6 & 0.1 & -1.2 & - & $8.58 \mathrm{~cm} \mathrm{~s}^{-1}$ & $14(4) \mathrm{cm} \mathrm{s}^{-1}$ & $14.27 \mathrm{~cm} \mathrm{~s}^{-1}$ \\
\hline
\end{tabular}

experimental data made before, as well as the particle tracking model. The most critical parameter affecting the particle movement is the velocity and temperature distribution in the room. These distributions were compared with an experimental study by Olesen et al. (1980). Individual verifications were made for both floor heating and radiator heating systems where temperature changes were given in Fig. 3, which compared the simulation data with measurements made by Olesen et al. (1980) in the direction that the measurements data had been collected.

The velocity values at the measured points by Olesen et al. (1980) and the numerical results' velocity data have been compared in Table 2 . It can be said that the velocity values calculated in the floor heating system are close to the values in the experimental study. In contrast, there is a difference between the calculated and measured values for the radiator heating system where there is only one value to compare. However, the calculated value is within one standard deviation range of the measured value and the velocity value was found close to the value calculated by previous studies (Sevilgen and Kilic, 2011) in the measurement coordinates given radiator heating system.

The results were obtained by using meshes with different element numbers to provide mesh independence. Accordingly, in the floor heating system, the results did not change after 2300000 elements in the simulations where tested mesh sizes were 478000, 1000000, 2300000, 3100000 and 4000000 elements in the calculations. In the radiator heating system, mesh sizes with 486000 , $1400000,3200000,4000000$ and 6000000 elements were tested and it was observed that the results did not change after 3200000 elements. In both heating systems, tetrahedral type network structures were used.

Experimental data performed by Chen et al. (2006) were used to compare with simulation results to validate the particle tracking model. Although the room in the study by Chen et al. (2006) is different from the room investigated in this study due to the lack of experimental data to compare particle concentrations. Therefore, a different geometry was used in this study to validate the DPM model like other researchers (Agirman et al., 2020; Zhang et al., 2021; Zhao and You, 2021). According to the comparison given in Fig. 4, it can be said that the particle tracking method is reliable enough to obtain realistic results.

\section{RESULTS AND DISCUSSION}

It has been observed that the velocity and temperature distribution formed by the radiator 

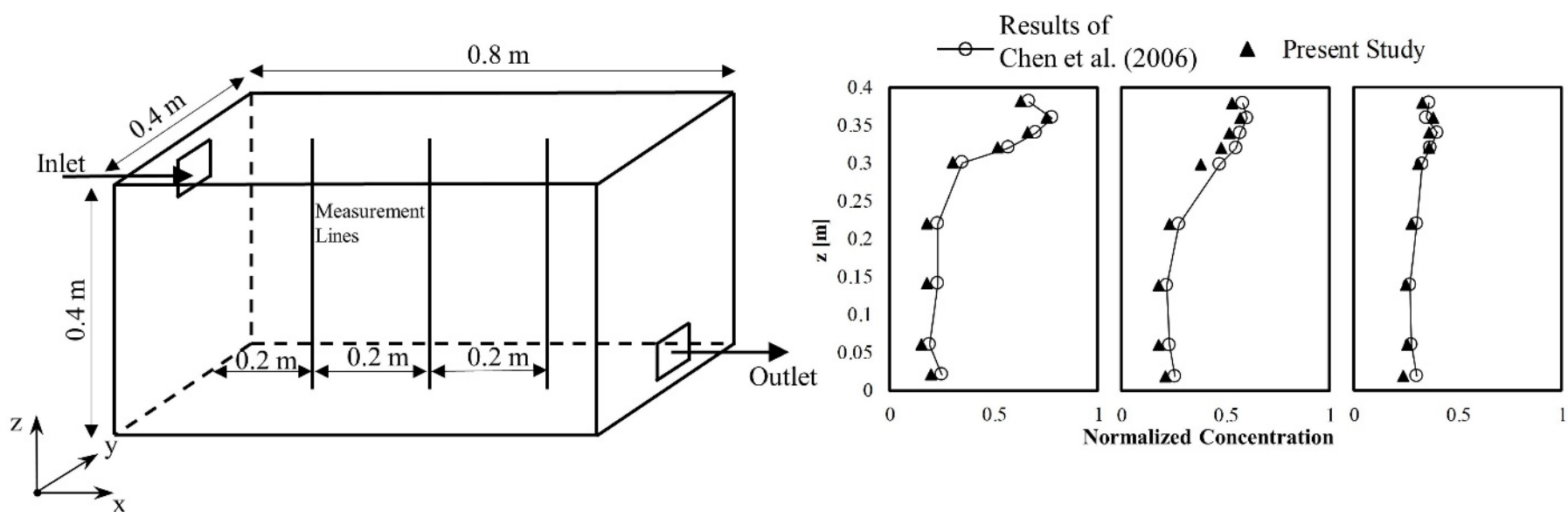

Fig. 4. Comparison of particle model with Chen et al. (2006).

and floor heating systems in a room are quite different, as well as particle distributions. It is seen that the air change rate is also an essential parameter in air movements in the room. Zero air change may positively contribute to energy consumption, but its adverse effects on indoor air quality should not be ignored.

\subsection{Velocity and Temperature Distribution}

Although hot water is used in both heating systems, the floor heating system's water temperature is lower than the radiator system due to the large heat transfer surface area of floor heating systems. Similarly, the water temperature in the radiator heating system is much higher than the floor heating system. As it is known, the greater the temperature difference between the heating surface and the air, the higher the speed of air movement due to the density difference. This phenomenon must be taken into account when comparing the velocity values of heating systems. Fig. 5 shows the velocity contours formed in the middle of the room $(z=-1.2 \mathrm{~m})$ of underfloor heating and radiator heating systems. The two surfaces' temperature in the floor heating system significantly affects the air movements caused by the density difference in the room. These surfaces are windows and floor surfaces. While the air movement is downward since the window surface is colder than the indoor air, the air movement near the floor is upward because it is warmer than the indoor air. These two air streams in different directions combine and move towards the back wall and a vortex is formed in the middle of the room. In contrast to the underfloor heating system, the radiator heating system's air movements are only related to
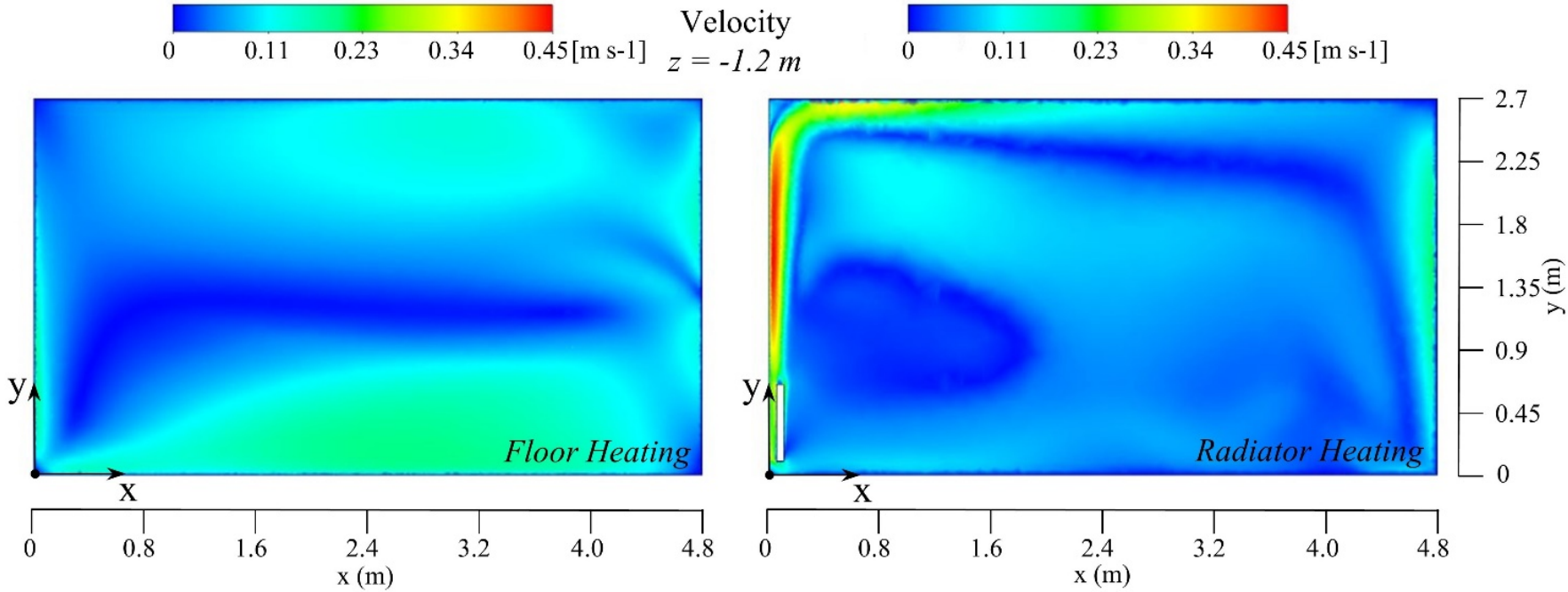

Fig. 5. Comparison of velocity contours in the middle of the room $(z=-1.2 \mathrm{~m})$. 


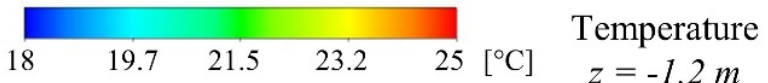

$\begin{array}{lllll}18 & 19.7 & 21.5 & 23.2 & 25\end{array}\left[{ }^{\circ} \mathrm{C}\right]$
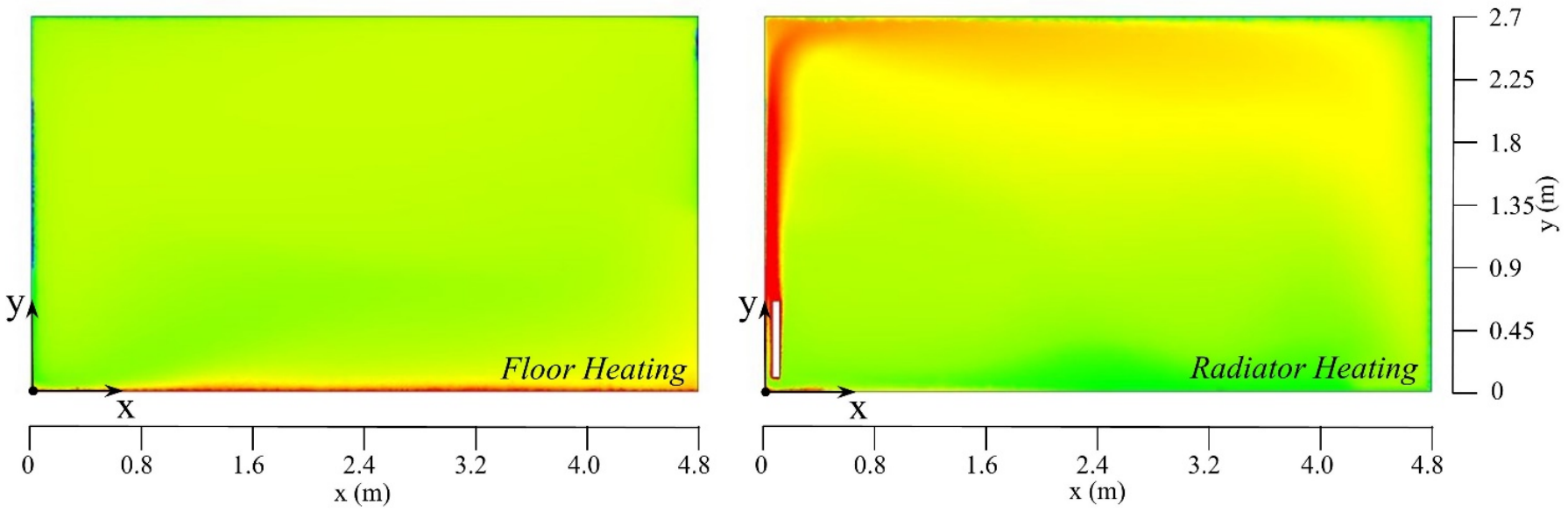

Fig. 6. Comparison of temperature contours in the middle of the room $(z=-1.2 \mathrm{~m})$.

the radiator surface. In the radiator heating system, the air whose density decreases by contacting the hot radiator surface moves upwards in front of the window and follows the ceiling surface. Then it moves towards the back wall and from there to the floor surface. Finally, it reaches the radiator and rises again.

The effect of air movements can be seen when the temperature distribution in the room is examined (Fig. 6). In the floor heating system, a more homogeneous temperature distribution has been observed in the room due to minor temperature differences. In contrast, the air temperature in contact with the radiator is much higher than the air temperature contacting the floor heating system's hot surface. Thus, the temperature difference between the ceiling and the floor surface in a radiator heating system is higher than that of a floor heating system.

\subsection{Particle Concentration Variation}

The particle concentration variation by time was given in Fig. 7 in case particle diameter was $1 \mu \mathrm{m}$ and $10 \mu \mathrm{m}$ and randomly distributed in the room with a concentration of $100 \mu \mathrm{g} \mathrm{m}^{-3}$. It has been observed that if particles are dispersed in the room, the floor heating system removes these particles from the environment faster than the radiator heating system. Similar results were obtained by Golkarfard and Talebizadeh (2014), but particle removal duration was different due to dissimilarities from this case. The most important reason for this is they made a particle charge at the height of $0.01 \mathrm{~m}$ from the floor, while the particles were homogeneously distributed in this study. Additionally, it could be said that room sizes also affect the results. Dehghan and Abdolzadeh (2018), who worked with the same room geometry with this study, stated that the particle phase
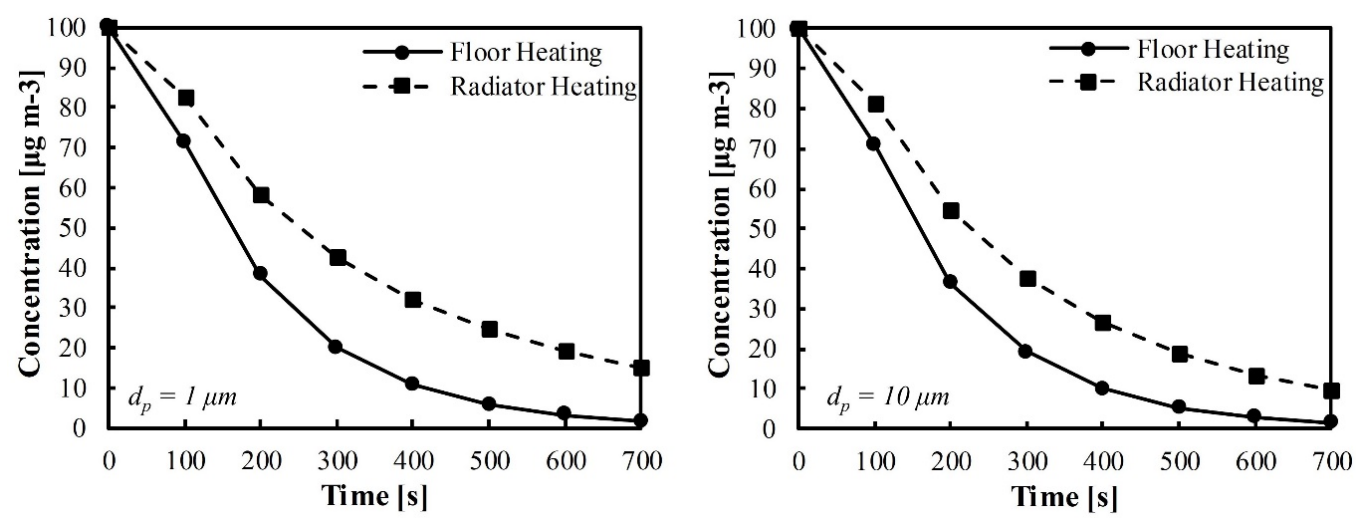

Fig. 7. Comparison of average concentration rates during $700 \mathrm{~s}$. 


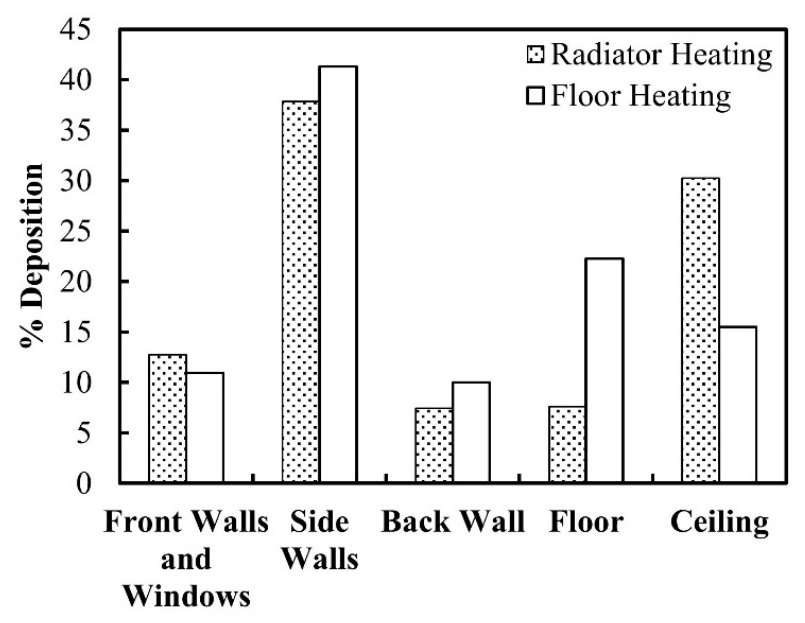

Fig. 8. Deposition rates of room surfaces.

reached steady-state conditions at the end of $640 \mathrm{~s}$. They also obtained similar results reported in this study and noted that the floor heating system's deposition rate was higher than the radiator heating system.

It could be said that the particle diameter has little effect, especially in the floor heating system where the particle diameter does not affect particles' removal rate. On the other hand, it can be said that the increase in the particle diameter slightly accelerates the deposition process of the particles due to the effect of gravity forces in the radiator heating system. The same result has been presented by Dehghan and Abdolzadeh (2018). Using a radiator heating system in environments where small particles present intensely will cause them to stay in the air for a longer time in the room.

The deposition rates of particles on different surfaces were given in Fig. 8. Particles adhere to vertical surfaces similarly for both heating systems, while other deposition characteristics were observed in horizontal walls. Particles deposited more to the ceiling and floor surfaces in the radiator and floor heating systems, respectively, due to different air movements in the room affecting particle movements. In an environment with zero air change rate, if a radiator heating system is used, the air moves upwards rapidly from the area where the radiator is located, and if the floor heating system is used, it moves more slowly towards the back wall above the floor (Fig. 5). Therefore, particles accumulate more on the floor heating system floor and the ceiling in the radiator heating system.

The particle concentration variation by time in the middle plane $(z=-1.2 \mathrm{~m})$ of the room is given in Fig. 9. In the floor heating system, particles concentrate in the room center, approximately $1 \mathrm{~m}$ height from the floor after $100 \mathrm{~s}$, while in the radiator heating system, particles concentrate near the front wall where the radiator is located. Ghasemi et al. (2020) has also measured high particle concentration values in the same location (just in front of the radiator) for the radiator heating system. It can be said that the reason for this is the rotating flow in front of the radiator. In this location, air velocity drops and the movement of particles slow down. Thus, concentration values increase. While the particle concentration in the floor heating system drops rapidly in almost every part of the presented plane, the particle concentration in front of the radiator is higher than the other room locations even after 700 seconds in the radiator heating system.

\subsection{Effect of Particle Source Location}

Heating system response on particle concentrations if a particle source exists is notably different from the case that particles are homogeneously distributed in the room, as mentioned above. Although the floor heating system performs better than the radiator heating system regarding cleaning the particles in the environment, it distributes the particles better in the room, especially if there is a pollutant source close to the floor. Accordingly, the concentration values are much higher than the radiator heating system (Figs. 10 and 11). The highest CR rate was calculated when the particle source is in the room center and close to the window. The vortex 
formed in the middle of the room causes particles to gathered here in the floor heating system, while the particles move towards front walls and move upwards just in front of windows in the radiator system. Additionally, when the particle source is close to the right wall, the CR value is above 1 at the back, while the CR value at the front of the room is higher than 1 when the particle

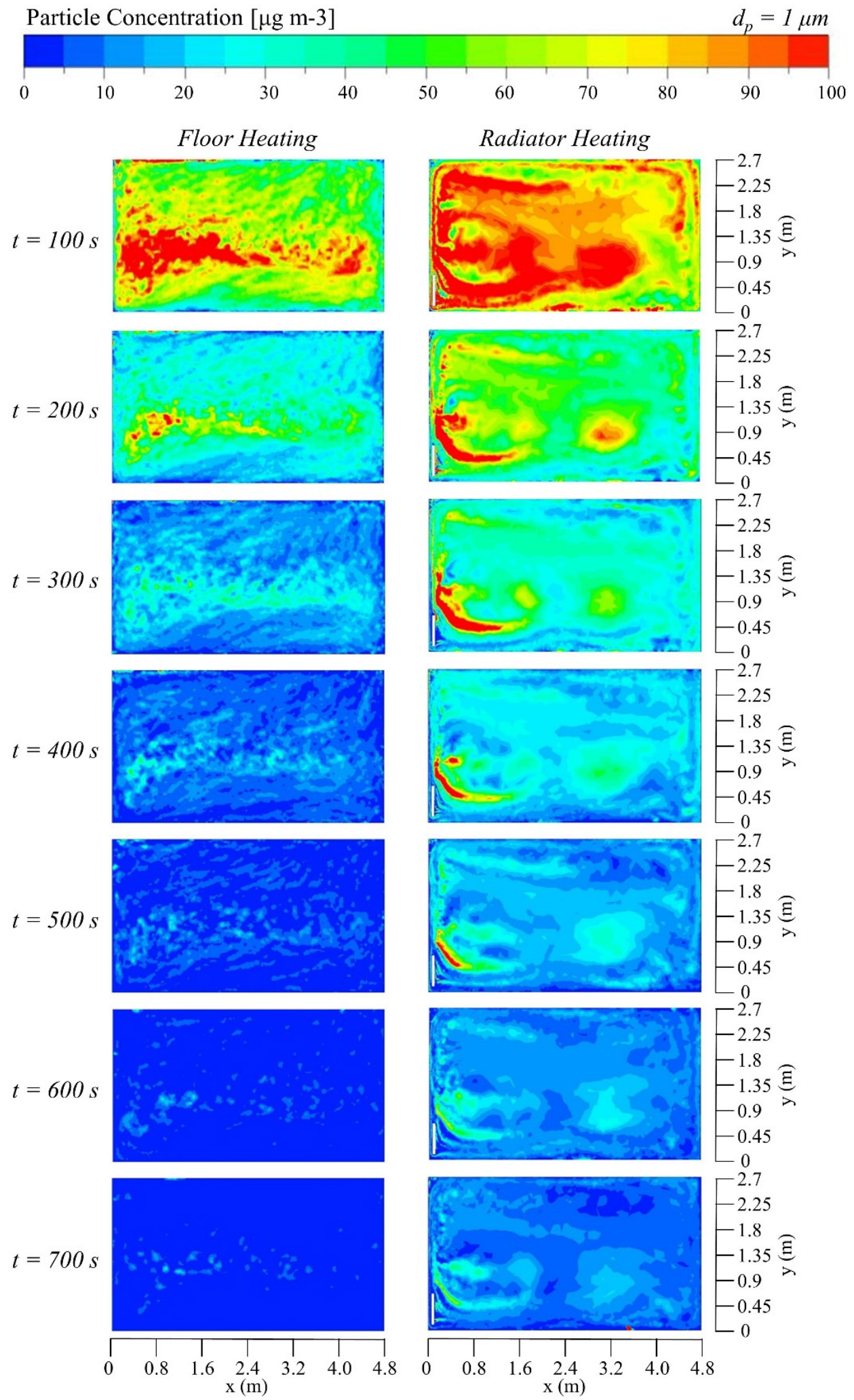

Fig. 9. Particle concentration contours in the middle of the room $(z=-1.2 \mathrm{~m})$. 

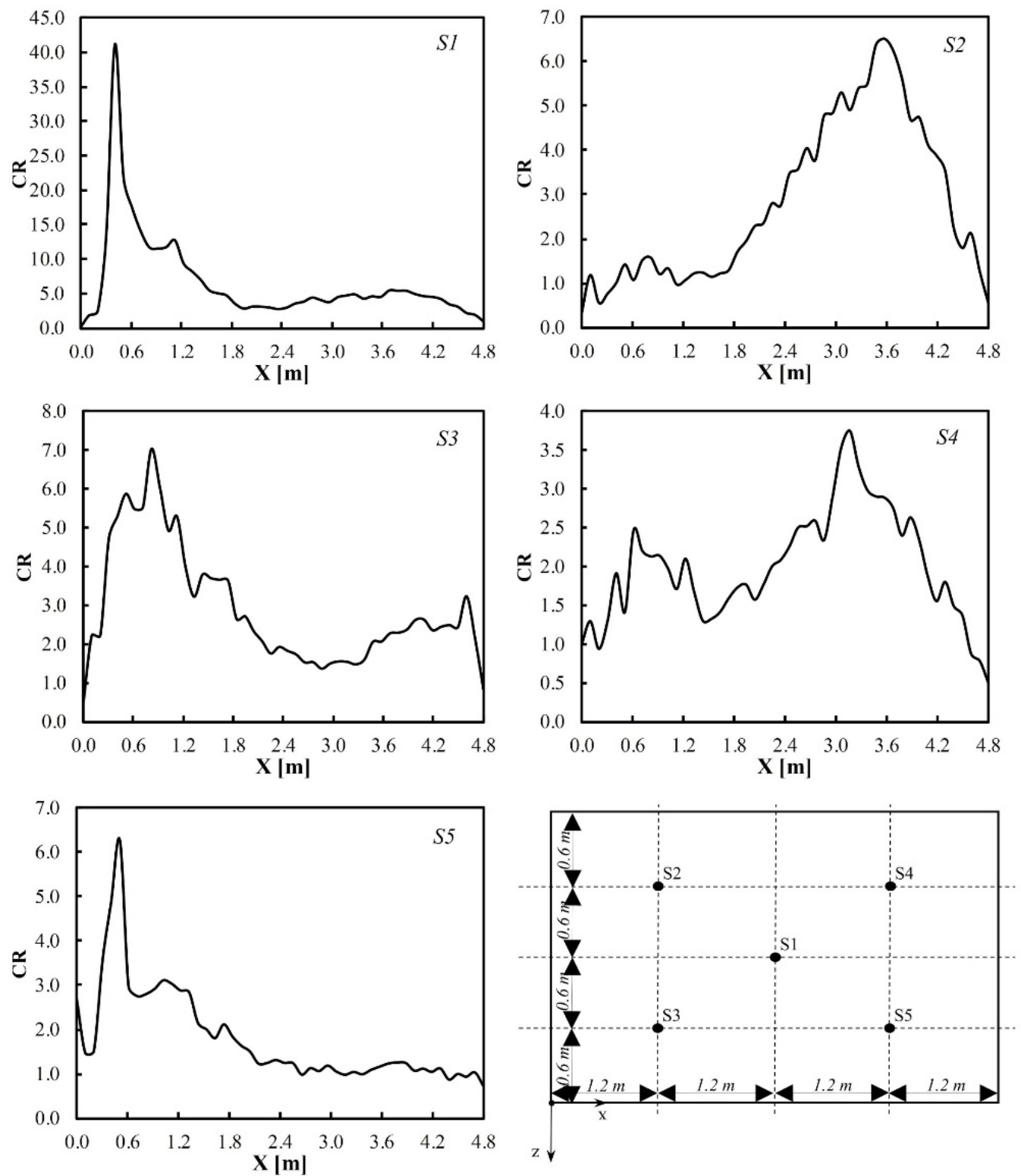

Fig. 10. Particle concentrations rate comparison of two heating systems with particle pollutant source locations.

source is close to the left wall. When the CR values in the $X$ and $Y$ directions are compared (Fig. 11), the particle concentration in the floor heating system is higher. This difference is significant, especially close to the particle source.

It has been observed that the particle source's location affects the particle concentration in the room and the deposition characteristics of the particles to the room surfaces. The deposition rates of the particles were given in Fig. 12. As seen from the figure, the particles mostly adhered to the floor surface and the side walls in the floor heating system. It was determined that the proportion of particles adhering to the front walls and window surface remained relatively low compared to other room surfaces. Unlike the floor heating system, the particle source's location significantly affects the particles' adhesion behavior to the surfaces in the radiator heating system. Particle deposition properties depend on whether the particle source is close to the window (S2 and S3) or close to the back wall (S4 and S5). When the particle source is close to the window, the particles mostly deposit to the sidewalls, whereas if the particle source is close to the rear wall, the particles stick to the floor surface. If the particle source is in the center of the room, almost $80 \%$ of the particles accumulate on the ground. 

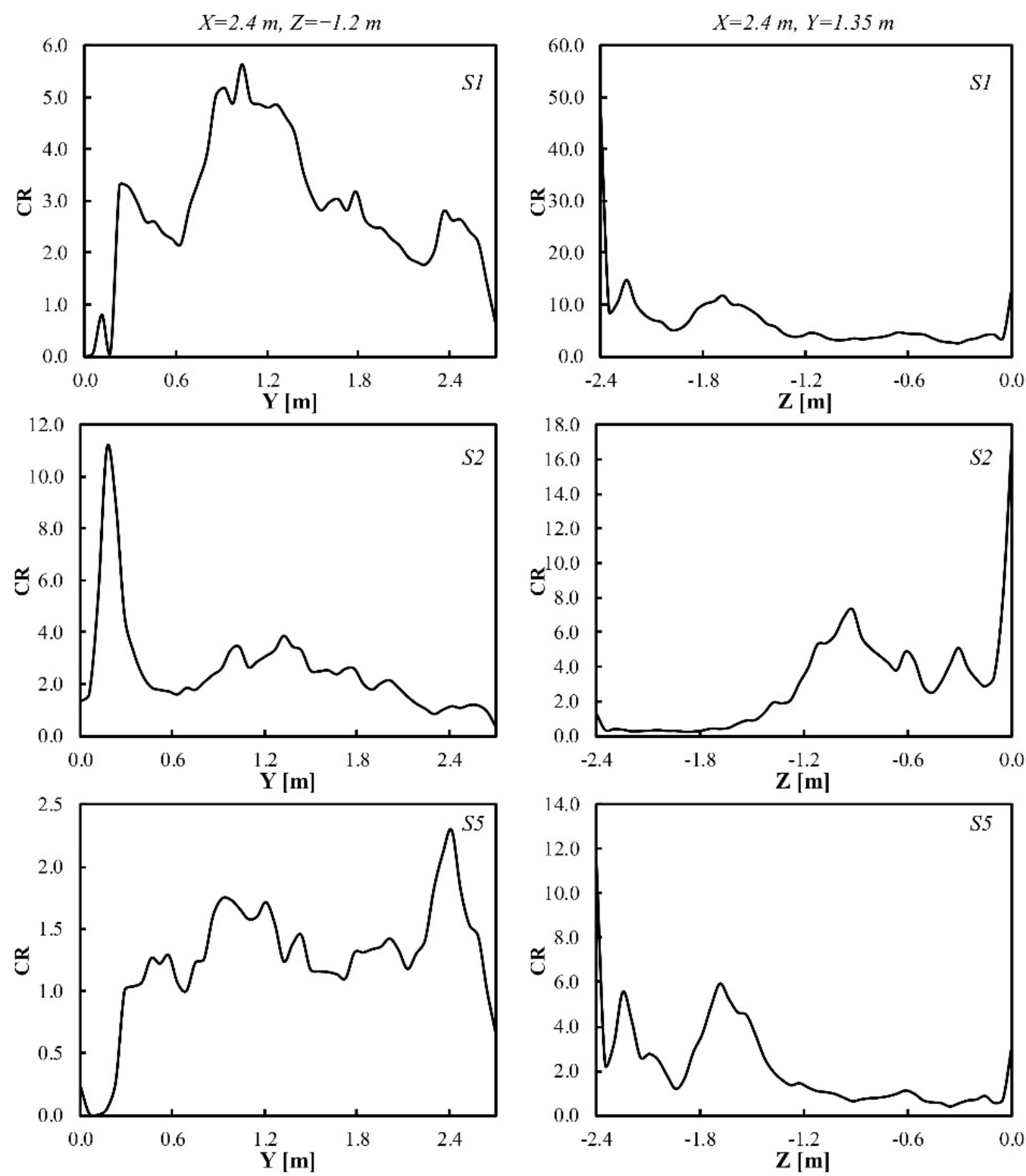

Fig. 11. Particle concentrations rate comparison of two heating systems in y and z direction.

\section{CONCLUSIONS}

Many people try to insulate their windows and doors to cut down their energy costs by reducing heat losses due to leakage. Particle movements in environments with almost zero air exchange are quite different from conditions with ideal ventilation. It is clear that the heating system used under these conditions also significantly affects the particle concentration. Therefore, underfloor heating and radiator heating systems were compared in terms of particle concentrations in zero air change rates and the following results were obtained.

- The velocity and temperature distributions that occur in the room differ significantly from the heating systems. Particle movements in the room are a function of the heating systems due to variation in velocity and temperature profiles.

- If particles are dispersed in the room homogeneously, it has been observed that in the floor heating system, the particle removing performance from the room is higher than the radiator system and the particle removing time difference increase with smaller particle diameter. Under these conditions, approximately $40 \%$ of the particles adhere to the room's sidewalls in both heating systems. 

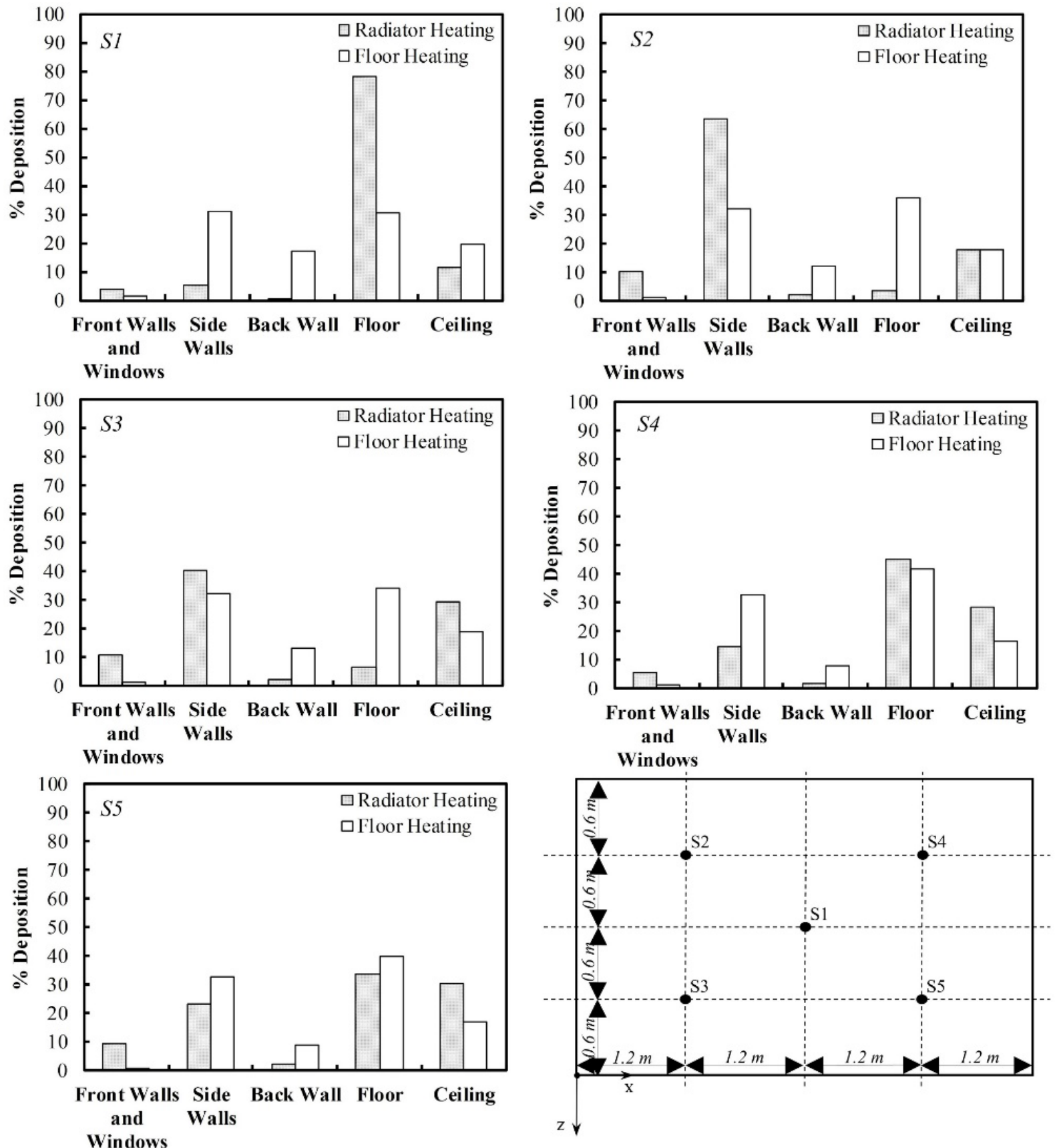

Fig. 12. Deposition characteristics of two heating systems with different particle source locations.

- $1 \mathrm{~m}$ height from the floor and the region just in front of the radiator was determined as critical particle concentration locations in the radiator heating and floor heating systems, respectively.

- If there is a particle source in the room, it can be said that the particle removing performance of the radiator heating system is better than the floor heating system. Particle concentration values of floor heating system can be 40 times higher than that of radiator heating system when particle source is in the center of the room.

The use of heat pumps for heating purposes in homes and offices is increasing with the developments in technology. Future studies should investigate the effect of different devices (e.g., cassette-type air conditioners, wall-mounted devices) on particle distribution in the indoor environment. In addition, the performance and effect of indoor air cleaning devices, the use of which has increased due to COVID-19, should be examined in detail. 
This study is supported by the Scientific and Technology Research Council of Turkey (TÜBITAK), under project number 118M222. The author would like to thank TÜBITAK for his support.

\section{REFERENCES}

Abdolzadeh, M., Alimolaei, E., Pustelnik, M. (2019). Numerical simulation of airflow and particle distributions with floor circular swirl diffuser for underfloor air distribution system in an office environment. Environ. Sci. Pollut. Res. 26, 24552-24569. https://doi.org/10.1007/s11356-01905651-8

Agirman, A., Cetin, Y.E., Avci, M., Aydin, O. (2020). Effect of laminar airflow unit diffuser size on pathogen particle distribution in an operating room. Sci. Technol. Built Environ. 27, 402-413. https://doi.org/10.1080/23744731.2020.1816405

Anthony, A.S., Verma, T.N. (2021). Numerical analysis of natural convection in a heated room and its implication on thermal comfort. J. Therm. Eng. 7, 37-53. https://doi.org/10.18186/thermal. 840007

Chen, F., Yu, S.C.M., Lai, A.C.K. (2006). Modeling particle distribution and deposition in indoor environments with a new drift-flux model. Atmos. Environ. 40, 357-367. https://doi.org/10.10 16/j.atmosenv.2005.09.044

Chen, X. (2018). Effect of heat-source geometry on distribution and deposition of particulates in a ventilated chamber. Particuology 36,174-184. https://doi.org/10.1016/j.partic.2017.03.004

Dehghan, M.H., Abdolzadeh, M. (2018). Comparison study on air flow and particle dispersion in a typical room with floor, skirt boarding, and radiator heating systems. Build. Environ. 133, 161-177. https://doi.org/10.1016/j.buildenv.2018.02.018

Ghasemi, M., Toghraie, D., Abdollahi, A. (2020). An experimental study on airborne particles dispersion in a residential room heated by radiator and floor heating systems. J. Build. Eng. 101677. https://doi.org/10.1016/j.jobe.2020.101677

Golkarfard, V., Talebizadeh, P. (2014). Numerical comparison of airborne particles deposition and dispersion in radiator and floor heating systems. Adv. Powder Technol. 25, 389-397. https://doi.org/10.1016/j.apt.2013.06.008

Han, Y., Hu, Y., Qian, F. (2011). Effects of air temperature and humidity on particle deposition. Chem. Eng. Res. Des. 89, 2063-2069. https://doi.org/10.1016/j.cherd.2011.02.001

Kazanci, O.B., Shukuya, M., Olesen, B.W. (2016). Exergy performance of different space heating systems: A theoretical study. Build. Environ. 99, 119-129. https://doi.org/10.1016/j.buildenv.2 016.01.025

Liu, J., Heidarinejad, M., Gracik, S., Srebric, J. (2015). The impact of exterior surface convective heat transfer coefficients on the building energy consumption in urban neighborhoods with different plan area densities. Energy Build. 86, 449-463. https://doi.org/10.1016/j.enbuild.201 4.10.062

Memarzadeh, F., Manning, A.P. (2002). Comparison of operating room ventilation systems in the protection of the surgical site. ASHRAE Trans. 108, 3-15.

Myhren, J.A., Holmberg, S. (2008). Flow patterns and thermal comfort in a room with panel, floor and wall heating. Energy Build. 40, 524-536. https://doi.org/10.1016/j.enbuild.2007.04.011

Olesen, B.W., Mortensen, E., Thorshauge, J., Berg-Munch, B. (1980). Thermal Comfort in a Room Heated by Different Methods. ASHRAE Trans. 86, 34-48.

Owen, M.K., Ensor, D.S., Sparks, L.E. (1992). Airborne particle sizes and sources found in indoor air. Atmos. Environ. 26, 2149-2162. https://doi.org/10.1016/0960-1686(92)90403-8

Pagels, J., Wierzbicka, A., Nilsson, E., Isaxon, C., Dahl, A., Gudmundsson, A., Swietlicki, E., Bohgard, M. (2009). Chemical composition and mass emission factors of candle smoke particles. J. Aerosol Sci. 40, 193-208. https://doi.org/10.1016/j.jaerosci.2008.10.005

Sadrizadeh, S., Holmberg, S. (2015). Effect of a portable ultra-clean exponential airflow unit on the particle distribution in an operating room. Particuology 18, 170-178. https://doi.org/10.10 16/j.partic.2014.06.002

Sakai, K., Ono, H., Kajiya, R. (2011). Validation of unsteady CFD analysis with actual measurement 
in a room with floor heating. 12 ${ }^{\text {th }}$ Int. Conf. Indoor Air Qual. Clim. 20114.

Sevilgen, G., Kilic, M. (2011). Numerical analysis of air flow, heat transfer, moisture transport and thermal comfort in a room heated by two-panel radiators. Energy Build. 43, 137-146. https://doi.org/10.1016/j.enbuild.2010.08.034

Tao, Y., Yang, W., Inthavong, K., Tu, J. (2020). Indoor particle inhalability of a stationary and moving manikin. Build. Environ. 169, 106545. https://doi.org/10.1016/j. buildenv.2019.106545

Wang, R., Wang, Y. (2020). Study on the Influence of Thermal Properties of Building Envelope on Indoor Pollutant Diffusion. Environ. Sci. Eng. 1113-1122. https://doi.org/10.1007/978-981-139520-8_115

World Health Organization (2006). WHO Air quality guidelines for particulate matter, ozone, nitrogen dioxide and sulfur dioxide : global update 2005 : summary of risk assessment. World Health Organization. https://apps.who.int/iris/handle/10665/69477

Ye, M., Serageldin, A.A., Nagano, K. (2020). CFD simulation on the thermal performance of a novel radiant ceiling cooling panel (RCCP) system with segmented and concave surface combined with forced ventilation. Energy Rep. 6, 1519-1524. https://doi.org/10.1016/j.egyr.2020.10.059

Ye, M., Serageldin, A.A., Radwan, A., Sato, H., Nagano, K. (2021). Thermal performance of ceiling radiant cooling panel with a segmented and concave surface: Laboratory analysis. Appl. Therm. Eng. 196, 117280. https://doi.org/10.1016/j.applthermaleng.2021.117280

Zhang, Y., Wang, Y., Wang, F., Xu, X., Wu, X. (2021). Numerical investigation on the transmission and dispersion of aerosols in a 7-stories building drainage system. Build. Environ. 201, 108009. https://doi.org/10.1016/j.buildenv.2021.108009

Zhao, B., Yang, C., Yang, X., Liu, S. (2008). Particle dispersion and deposition in ventilated rooms: Testing and evaluation of different Eulerian and Lagrangian models. Build. Environ. 43, 388397. https://doi.org/10.1016/j.buildenv.2007.01.005

Zhao, J. jing, You, X.Y. (2021). Probabilistic health risk assessment of exposure to carcinogens of Chinese family cooking and influence analysis of cooking factors. Sci. Total Environ. 779, 146493. https://doi.org/10.1016/j.scitotenv.2021.146493

Zhou, Y., Deng, Y., Wu, P., Cao, S.J. (2017). The effects of ventilation and floor heating systems on the dispersion and deposition of fine particles in an enclosed environment. Build. Environ. 125, 192-205. https://doi.org/10.1016/j.buildenv.2017.08.049 